\title{
Evaluation of dihydroquercetin-3-0-glucoside from Malbec grapes as copigment of malvidin-3-O-glucoside
}

\author{
Martín Fanzone $^{\mathrm{a}, *}$, Susana González-Manzano ${ }^{\mathrm{b}}$, Joaquín Pérez-Alonso ${ }^{\mathrm{b}}$, María Teresa Escribano-Bailón ${ }^{\mathrm{b}}$, \\ Viviana Jofré ${ }^{\mathrm{a}}$, Mariela Assof ${ }^{\mathrm{a}}$, Celestino Santos-Buelga ${ }^{\mathrm{b}}$

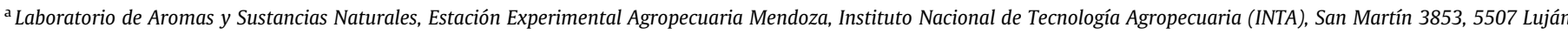 \\ de Cuyo, Mendoza, Argentina \\ ${ }^{\mathrm{b}}$ Grupo de Investigación en Polifenoles (GIP-USAL), Facultad de Farmacia, Universidad de Salamanca, Campus Miguel de Unamuno s/n, E-37007 Salamanca, Spain
}

\section{A R T I C L E I N F O}

\section{Article history:}

Received 20 August 2014

Received in revised form 18 November 2014

Accepted 20 November 2014

Available online 27 November 2014

Chemical compounds studied in this article:

Malvidin-3-O-glucoside (PubChem CID:

443652)

Dihydroquercetin-3-O-glucoside (PubChem

CID: 14187089)

Keywords:

Copigmentation

Dihydroflavonols

Anthocyanins

Color

Malbec

\begin{abstract}
A B S T R A C T
Malbec is a wine grape variety of great phenolic potential characterized for its high levels of anthocyanins and dihydroflavonols. To evaluate the possible implication of dihydroflavonols in the expression of red wine color through reactions of copigmentation or condensation, assays were carried out in wine model systems with different malvidin-3-0-glucoside:dihydroquercetin-3-O-glucoside molar ratios. The addition of increasing levels of dihydroquercetin-3-O-glucoside to a constant malvidin-3-O-glucoside concentration resulted in a hyperchromic effect associated with a darkening of the anthocyanin solutions, greater quantity of color and visual saturation, perceptible to the human eye. Copigmentation and thermodynamic measurements showed that dihydroquercetin-3-O-glucoside can act as an anthocyanin copigment, similar to other usual wine components like flavanols or phenolic acids, although apparently less efficient than flavonols. The high levels of dihydroflavonols existing in Malbec wines in relation to other non-anthocyanin phenolics should make this family of compounds particularly important to explain the color expression in Malbec young red wines.
\end{abstract}

(c) 2014 Elsevier Ltd. All rights reserved.

\section{Introduction}

Color is one of the most important quality parameters of red wine significantly influencing their sensory appreciation. In general, it is the first perceived characteristic, and therefore plays a key role in the process of decision-making of consumers, with preferences usually aimed toward intense coloring. Phenolic compounds, participating in the color of red wine, are extracted from grape skins and seeds and diffuse into must/wine during winemaking process (Boido et al., 2011; González-Manzano, Rivas-Gonzalo, \& Santos-Buelga, 2004). While anthocyanins are the pigments directly responsible for the color of red wine, other flavonoids and non-flavonoids are involved in its stabilization through reactions of copigmentation or condensation (Monagas \& Bartolomé, 2009).

\footnotetext{
* Corresponding author. Tel.: +54 261 4963020; fax: +54 2614963320

E-mail address: fanzone.martin@inta.gob.ar (M. Fanzone).
}

Anthocyanins are compounds with relatively low stability and their susceptibility to degradation is influenced by factors such as temperature, light, $\mathrm{pH}$, solvents, oxygen, non-covalent interactions with other anthocyanins (self-association) or colorless compounds (intermolecular copigmentation), coordination with metallic ions and covalent reactions with other compounds present in the medium. In particular, the copigmentation phenomenon is involved in the color variability observed in flowers and fruits (Goto \& Kondo, 1991), and it is also believed to play a relevant contribution in the color of red wines (Santos-Buelga \& De Freitas, 2009). Copigmentation consists of hydrophobic interactions $(\pi-\pi$ stacking) between the planar polarisable nuclei of the colored forms of the anthocyanins and other molecules (copigments). Copigmentation complexes adopt a sandwich configuration that protects the flavylium chromophore from the nucleophilic attack of water, thus reducing the formation of colorless hemiketal and chalcone forms. The final result is that anthocyanin solutions show a more intense color than theoretically could be expected according to $\mathrm{pH}$ value of the media (Escribano-Bailón \& Santos-Buelga, 
2012). In addition to this intermolecular interaction, other copigmentation mechanisms have also been described, such as the association between the central anthocyanin chromophore and aromatic acyl residues from its own molecule (intramolecular copigmentation), the self-association of anthocyanins, and the interactions involving metal cations (Dangles, Saito, \& Brouillard, 1993a; Fernández, Santamaría, \& Sparza, 2006). As a result of this phenomenon, the absorption spectra of copigmented solutions usually display a shift of the maximum wavelength $\left(\lambda_{\max }\right)$ in the visible range (bathochromic effect) accompanied by an increase in absorbance (hyperchromic effect). The extent of these effects depends on different factors such as $\mathrm{pH}$, temperature, ethanol content, the nature of the chromophore and the copigment, or the pigment/copigment molar ratio, among others (Baranac, Petranovic, \& Dimitric-Markovic, 1996; Boulton, 2001; Escribano-Bailón \& Santos-Buelga, 2012).

Copigmentation processes are of great oenological interest, as they are vital for the understanding of the relationship between grape composition and color in young red wines (Boulton, 2001). Also, different authors have pointed out their possible participation in the color evolution during wine ageing, constituting the first stage in the formation of more stable pigments (Brouillard \& Dangles, 1994), having been shown that young red wines with higher percentages of copigmented color lead to wines with higher percentages of polymeric color (Lorenzo, Pardo, Zalacain, Alonso, \& Salinas, 2005).

Among red wine components, flavonoids and hydroxycinnamoyl derivatives appear to be most promising compounds to act as anthocyanin copigments. In assays carried out in wine model solutions, flavonols showed a greater potential of copigmentation, followed by hydroxycinnamic acids and by flavanols (GómezMíguez, González-Manzano, Escribano-Bailón, Heredia, \& SantosBuelga, 2006).

In order to interpret the influence of different factors on the wine color and its evolution during maturation, several studies with model solutions using malvidin-3-O-glucoside (the majority anthocyanin in red wines) as a pigment and distinct copigments (e.g., caffeic acid, ferulic acid, (+)-catechin, (-)-epicatechin, quercetin, procyanidins) have been conducted. However, in many cases the concentrations of pigment and cofactors and the molar ratios tested were higher than those that can be found in wines (Berké \& De Freitas, 2005; Dimitric-Markovic, Petranovic, \& Baranac, 2000; Lambert, Asenstorfer, Williamson, Iland, \& Jones, 2011).

In previous studies by our research group about phenolic composition of Malbec variety (Vitis vinifera L.), the presence of dihydroflavonols as relevant compounds between low molecular weight phenolics was observed (Fanzone, 2012). According to the literature, these compounds are especially present in white varieties (Masa, Vilanova, \& Pomar, 2007) and play functional roles in grape berries (Landrault et al., 2002), but they represent a smaller fraction of the flavonoids in most wines. However, relatively high levels of dihydroflavonols have been found in Malbec red grapes and wines from the region of Mendoza (Argentina), which could represent a distinctive feature of this variety (Fanzone, Zamora, Jofré, Assof, \& Peña-Neira, 2011; Fanzone et al., 2012). In all cases, dihydroquercetin-3-O-glucoside was the major compound with higher concentrations $(>40 \mathrm{mg} / \mathrm{L}$ ) than the individual non-anthocyanin flavonoids and non-flavonoids phenolics identified (Fanzone, 2012). Due to these results and to absence of information on its behavior at oenological/technological level, it is interesting to assess its copigmentation potential. In this context, the aim of the present study was to evaluate the interaction between dihydroquercetin-3-O-glucoside and malvidin-3-O-glucoside and to explore its effects on color parameters in model solutions with different pigment/copigment molar ratios.

\section{Materials and methods}

\subsection{Standards and reagents}

Sodium chloride and hydroxide were purchased from Anedra (Buenos Aires, Argentina). Ethyl acetate was acquired from Sintorgan (Buenos Aires, Argentina). Sodium sulfate anhydrous, hydrochloric acid, tartaric acid, formic acid, ethanol, chromatography grade methanol and acetonitrile were purchased from Merck (Darmstadt, Germany). All reactive were analytical grade or superior. Ultra pure water was obtained from a RiO/Elix3-Sinergy185 purification system (Millipore, Sao Pablo, Brazil). Cellulose filter ( $3 \mu \mathrm{m}$ pore size) was supplied by Microclar (Buenos Aires, Argentina).

The pigment malvidin-3-O-glucoside (Mv3gl) was obtained in the laboratory from skins of Malbec grapes using extraction with methanol: $\mathrm{HCl} 1 \mathrm{~N}(95: 5, \mathrm{v} / \mathrm{v})$ and further purification by semipreparative HPLC using a reversed-phase column, as described by Heredia, Rivas-Gonzalo, Vicario, and Santos-Buelga (1998). The isolated compound was then freeze-dried and its purity examined by HPLC-DAD-ESI/MS.

\subsection{Extraction and isolation of dihydroquercetin-3-O-glucoside (DHQ3gl)}

This compound was isolated from Malbec grape skins of Uco Valley (Mendoza, Argentina). The skins were manually separated and extracted with methanol:water:formic acid (50:48.5:1.5, v/v/ v) following the method proposed by Lago-Vanzela, Da-Silva, Gomes, García-Romero, and Hermosín-Gutiérrez (2011). The methanol extracts were concentrated under vacuum to evaporate the alcohol, and then were submitted to repeated liquid-liquid extractions with ethyl acetate. The organic fractions were combined, dehydrated with sodium sulfate anhydrous, filtered through a $3 \mu \mathrm{m}$ pore size cellulose filter, and evaporated to dryness under vacuum at $35^{\circ} \mathrm{C}$. The solid residue was dissolved in methanol:water $(20: 80, \mathrm{v} / \mathrm{v})$, and then was subjected to semi-preparative HPLC to purify DHQ3gl. The equipment employed was an Agilent 1260 Infinity Analytical-Scale Purification System with a diode array detector (G1315D), a preparative pump (G1361A), a fraction collector (G1364B), and an autosampler (G2258A) (Agilent Technologies, Waldbronn, Germany). Separation was performed on an Agilent preparative C18 column $(150 \mathrm{~mm} \times 21.2 \mathrm{~mm}$ i.d., $5 \mu \mathrm{m}$; Agilent, Waldbronn, Germany) at $25^{\circ} \mathrm{C}$. A gradient consisting of solvent A ( $0.1 \%$ formic acid) and solvent B (methanol) was applied at a flow rate of $15 \mathrm{~mL} / \mathrm{min}$ from 0 to $55 \mathrm{~min}$ as follows: $85 \% \mathrm{~A}$ and $15 \%$ B from 0 to $5 \mathrm{~min}, 15-25 \%$ B from 5 to $10 \mathrm{~min}, 25 \%$ B from 10 to $25 \mathrm{~min}, 25-35 \%$ B from 25 to $40 \mathrm{~min}, 35 \%$ B from 40 to $50 \mathrm{~min}$, and $35-100 \%$ B from 50 to $55 \mathrm{~min}$; followed by a final wash with $100 \%$ methanol and re-equilibration of the column. Detection was carried out at 280,360, and $520 \mathrm{~nm}$. The fractions that contained DHQ3gl were mixed, concentrated under vacuum and freeze-dried. The identity and purity of the isolated compound was checked by HPLC-DAD-ESI/MS.

\subsection{Preparation of model solutions}

In order to evaluate the magnitude of copigmentation between Mv3gl/DHQ3gl and to explore its effects on color parameters, stock solutions of both compounds were prepared at a concentration of 4.1 mM. A wine-like medium containing $5 \mathrm{~g} / \mathrm{L}$ of tartaric acid in $12 \%$ of ethanol, buffered with $\mathrm{NaOH}$ to $\mathrm{pH} 3.6$, and ionic strength adjusted to $1 \mathrm{M}$ with $\mathrm{NaCl}$, was used. The working solutions were prepared by mixing and adequate dilution of the stock solutions, and they consisted of a reference solution containing $200 \mathrm{mg} / \mathrm{L}$ 
(0.41 mM) of Mv3gl, and four copigmented solutions with the same anthocyanin concentration and increasing concentrations of copigment (pigment/copigment molar ratio 1:0.5, 1:1, 1:2 and $1: 5)$. All the solutions were prepared in triplicate, transferred to glass vials, closed and stored in darkness at $25^{\circ} \mathrm{C}$.

\subsection{Copigmentation and colorimetric measurements}

The magnitude of the copigmentation was estimated by comparison of the absorbance at $520 \mathrm{~nm}$ from the reference solution $\left(A_{0}\right)$ and the absorbance at $520 \mathrm{~nm}$ from the copigmented solutions $(A)$, and expressed as the percentage, according to the following equation (Eq. (1)) (Boulton, 1996):

$\left[\left(A-A_{0}\right) / A_{0}\right] \times 100$

Spectral measurements were performed over the entire visible range (between 380 and $770 \mathrm{~nm}$ ) in $2 \mathrm{~mm}$ path length glass cells at $25^{\circ} \mathrm{C}$, by using a Hewlett Packard UV-Vis HP-8452 spectrophotometer (Agilent Technologies, Palo Alto, CA). The CIELAB parameters $\left(L^{*}, a^{*}, b^{*}, C_{\mathrm{ab}}^{*}, h_{\mathrm{ab}}^{*}\right)$ and a CIELUV parameter $\left(s_{\mathrm{w}}^{*}\right)$ were determined by using the original software Cromalab (Heredia, Alvarez, González-Miret, \& Ramírez, 2004). The illuminant D65 and $10^{\circ}$ Standard Observer were taken as references. The absolute color variation induced by copigmentation $\left(\Delta E_{\mathrm{ab}}^{*}\right)$ was assessed between the color of the copigmented (cp) and reference (p) anthocyanin solutions, as follows (Eq. (2)) (Gordillo, Rodríguez-Pulido, Escudero-Gilete, González-Miret, \& Heredia, 2012):

$\Delta E_{\mathrm{ab}}^{*}(\mathrm{cp}-\mathrm{p})=\left(\left(L_{\mathrm{cp}}^{*}-L_{\mathrm{p}}^{*}\right)^{2}+\left(a_{\mathrm{cp}}^{*}-a_{\mathrm{p}}^{*}\right)^{2}+\left(b_{\mathrm{cp}}^{*}-b_{\mathrm{p}}^{*}\right)^{2}\right)^{1 / 2}$

In the same way, the absolute lightness, chroma, and hue differences $\left(\Delta L^{*}, \Delta C_{\mathrm{ab}}^{*}\right.$ and $\left.\Delta h_{\mathrm{ab}}^{*}\right)$ were used to assess the trend of the color changes induced by copigmentation. Furthermore, the relative contribution of the three color attributes that make up the total CIELAB color difference was also calculated to compare the copigmentation effect according to different factors. The weight of each color attribute ( $\% \Delta L, \% \Delta \mathrm{C}$ and $\% \Delta H$ ) was calculated as indicated by Gordillo et al. (2012). Samples of working solutions for the analysis were taken at $2 \mathrm{~h}$ and after 2 months of storage at $25^{\circ} \mathrm{C}$.

\subsection{Thermodynamic measurements}

In order to determine the apparent hydration constant, model solutions of Mv3gl were prepared at a concentration of $0.1 \mathrm{mM}$ and at different $\mathrm{pH}$ values (range 0.9-4.0) in citrate-phosphate buffer with $12 \%$ of ethanol, and the ionic strength adjusted to $1 \mathrm{M}$ with $\mathrm{NaCl}$. These solutions contained increasing concentrations of DHQ3gl, to obtain molar ratios Mv3gl:DHQ3gl of 1:0, $1: 0.5,1: 1,1: 2,1: 5$. The solutions were kept for $2 \mathrm{~h}$ at $25^{\circ} \mathrm{C}$ to ensure complete hydration equilibrium and then their UV-Vis spectra were recorded as previously described. All assays were made in triplicate.

The value of first-order apparent rate constant of the hydration reaction $(K)$ is the sum of the hydration $\left(K^{\prime}{ }_{h}\right)$ and proton transfer $\left(K_{\mathrm{a}}\right)$ constants $\left(K=K_{\mathrm{h}}{ }_{\mathrm{h}}+K_{\mathrm{a}}\right)$, and was deduced from plotting $A_{0} /$ $\left(A_{0}-A\right)$ versus $10^{-\mathrm{pH}}$, resulting in a straight line, from the intercept to slope ratio, in accordance with the Eq. (3) (Dangles, Saito, \& Brouillard, 1993b):

$A_{0} /\left(A_{0}-A\right)=\left(K_{h}^{\prime}+K_{a}\left(1-r_{a}\right)\right)+\left(10^{-\mathrm{pH}}\right) /\left(K_{h}^{\prime}+K_{a}\left(1-r_{a}\right)\right)$

In this equation, $A_{0}$ is the absorbance of Mv3gl solution at strongly acidic condition $(\mathrm{pH} \leqslant 1)$, in which the anthocyanin is in pure flavylium form; $A$ is the absorbance of the copigmented solution at a slightly acidic $\mathrm{pH}$ (3.6), similar to that found in wines; and $r_{\mathrm{a}}$ is the ratio of molar absorption coefficients of the same pigment in its quinoidal form and in its flavylium form.

Also, it was calculated the equilibrium constant of copigmentation $\left(K_{\mathrm{c}}\right)$ according to the Eq. (4) (Brouillard, Mazza, Saad, Albrechtgary, \& Cheminat, 1989):

$$
\left(A-A_{0}\right) / A_{0}=K_{\mathrm{c}} r\left[C_{\mathrm{p}}\right] n
$$

where $A$ is the absorbance $\left(\lambda_{\max }\right)$ of the copigmented solution at the specific $\mathrm{pH} ; A_{0}$ is the absorbance of Mv3gl solution at the same $\mathrm{pH} ; r$ is the ratio $\varepsilon_{\mathrm{AH}} / \varepsilon_{\mathrm{AHCp}}$ (ratio of molar absorption coefficients of flavylium ion and flavylium ion-copigment complex) and can be estimated by the ratio between the absorbance of the anthocyanin solution in strongly acidic media $(\mathrm{pH}<1)$ and the absorbance of the same solution at a copigment:pigment molar ratio of $1000: 1 ; C_{\mathrm{p}}$ is the copigment concentration; and $n$ is the stoichiometric ratio between components in the complex of copigmentation. Representing $\ln \left(A-A_{0}\right) / A_{0}$ against $\ln \left[C_{\mathrm{p}}\right]$, results in a straight line whose slope is $n$ and the ordinate at the origin is $\ln K_{\mathrm{c}} r$ (Eq. (5))

$\ln \left(A-A_{0}\right) / A_{0}=\ln K_{\mathrm{c}} r+n \ln \left[C_{\mathrm{p}}\right]$

Finally, Gibbs energy variation $\left(\Delta G^{0}\right)$ was calculated by $\Delta G^{0}=$ $-R T \ln K_{\mathrm{c}}$; where $R$ is the universal gas constant; $T$ is the temperature; and $K_{\mathrm{c}}$ is the equilibrium constant of copigmentation, explained above. In order to standardize the results the thermodynamic parameters were calculated at $T=298 \mathrm{~K}$.

\subsection{HPLC-DAD-ESI/MS analyses}

HPLC analyses were carried out using an Agilent 1100 Series chromatographic system provided with a diode array detector (G1315A), quaternary pump (G1316A), autosampler (G1313A), and data treatment station (Agilent Technologies, Waldbronn, Germany). Separation was performed on an AQUA ${ }^{\circledR}$ Phenomenex reversed phase $\mathrm{C} 18$ column $(150 \mathrm{~mm} \times 4.6 \mathrm{~mm}$ i.d., $5 \mu \mathrm{m}$; Phenomenex Inc., Torrance, CA) at $25^{\circ} \mathrm{C}$. The solvents were (A) $0.1 \%$ formic acid in water $(v / v)$ and (B) acetonitrile. The following linear gradient was used: $15 \%$ B from 0 to $5 \mathrm{~min}, 15-20 \%$ B from 5 to $10 \mathrm{~min}, 20-35 \%$ B from 10 to $20 \mathrm{~min}, 35-50 \%$ B from 20 to $30 \mathrm{~min}, 50-60 \%$ B from 30 to $32 \mathrm{~min}$, and $60 \%$ B for $5 \mathrm{~min}$, followed by washing and reconditioning of the column. The flow-rate was $0.5 \mathrm{~mL} / \mathrm{min}$ and the injection volume $50 \mu \mathrm{L}$. Double online detection was carried out in a diode array detector (DAD) using 280, 320,360 , and $520 \mathrm{~nm}$ as preferred wavelengths and a mass spectrometer (API 3200 Qtrap, Applied Biosystems, Darmstadt, Germany) connected to the HPLC system via the DAD cell outlet. For pigment analysis, MS spectra were recorded in positive ion mode from $\mathrm{m} / \mathrm{z} 100$ to 1500 . Zero grade air served as the nebulizer gas (40 psi) and as turbo gas $\left(600^{\circ} \mathrm{C}\right)$ for solvent drying (50 psi). Nitrogen served as the curtain (100 psi) and collision gas (high). Both quadrupoles were set at unit resolution. Enhanced MS (EMS) and Enhanced Product Ion (EPI) analyses were used for acquisition of full scan spectra and fragmentation patterns of the precursor ions, respectively. Setting parameters used for EMS mode were: ion spray voltage $5000 \mathrm{~V}$; declustering potential (DP) $41 \mathrm{~V}$, entrance potential $(\mathrm{EP}) 7.5 \mathrm{~V}$, collision energy $(\mathrm{CE}) 10 \mathrm{~V}$, and parameters for EPI mode were: DP $41 \mathrm{~V}$, EP $7.5 \mathrm{~V}$, CE $10 \mathrm{~V}$, and collision energy spread (CES) $0 \mathrm{~V}$. MS analyses of other phenolic compounds were performed in negative ion mode between $\mathrm{m} / \mathrm{z}$ 100 and 1000. Zero grade air served as the nebulizer gas (30 psi) and turbo gas for solvent drying $\left(400^{\circ} \mathrm{C}, 40 \mathrm{psi}\right)$. Nitrogen served as the curtain (20 psi) and collision gas (medium). Quadrupoles were set at unit resolution. EMS parameters were: ion spray voltage $-4500 \mathrm{~V}$; declustering potential (DP), $-50 \mathrm{~V}$; entrance potential (EP), $-6 \mathrm{~V}$; collision energy $(\mathrm{CE}),-10 \mathrm{~V}$; and cell exit 
potential (CXP) $-3 \mathrm{~V}$. EPI parameters were: DP $50 \mathrm{~V}$, EP $6 \mathrm{~V}, \mathrm{CE}$ $25 \mathrm{~V}$, and CES $0 \mathrm{~V}$.

\subsection{Statistical analysis}

Statistical analysis was assessed with Statgraphics Plus version 4.0 software (Copyright 1994-1999, Statistical Graphics Corp., Warrenton, VA). All the results were tested for homogeneity of variance using Cochran's test, and the differences between means evaluated by analysis of variance (ANOVA) and Tukey's multiplerange tests (TMRT). A $p<0.05$ was considered to be statistically significant.

\section{Results and discussion}

\subsection{Isolation and identification of $D H Q 3 g l$}

Dihydroquercetin-3-O-glucoside was isolated from the skins of Malbec grapes. The HPLC chromatogram, UV $\left(\lambda_{\max }\right.$ at $292 \mathrm{~nm}$ and $336 \mathrm{~nm}, \mathrm{sh}$ ) and mass spectra of the obtained compound are shown in Fig. 1. Both UV and mass spectra were coherent with those expected for the compound, with a fragmentation pattern showing product ions at $\mathrm{m} / \mathrm{z} 465\left([\mathrm{M}-\mathrm{H}]^{-}\right.$, molecular ion), 303 ([ $\left.\mathrm{Y}_{0}\right]^{-}$; dihydroquercetin), $285\left(\left[\mathrm{Y}_{0}-\mathrm{H}_{2} \mathrm{O}\right]^{-}\right), 257\left(\left[\mathrm{Y}_{0}-\mathrm{H}_{2} \mathrm{O}-\mathrm{CO}\right]^{-}\right)$, $229\left(\left[\mathrm{Y}_{0}-\mathrm{H}_{2} \mathrm{O}-2 \mathrm{CO}\right]^{-}\right), 211\left(\left[\mathrm{Y}_{0}-2 \mathrm{H}_{2} \mathrm{O}-2 \mathrm{CO}\right]^{-}\right)$and $151\left(\left[{ }^{1,3} \mathrm{~A}_{0}\right]^{-}\right.$; retro Diels-Alder fission) consistent with the one proposed by Abad-García, Garmón-Lobato, Berrueta, Gallo, and Vicente (2009) for dihydroflavonols. The estimated chromatographic purity of the isolated dihydroquercetin-3-O-glucoside was $96 \%$. This compound was used in the copigmentation assays discussed below.

\subsection{Copigmentation assays}

The study of the copigmentation between Mv3gl and DHQ3gl was performed at different pigment:copigment molar ratios $(1: 0.5 ; 1: 1 ; 1: 2$ and $1: 5)$ using wine model solutions of $\mathrm{pH} 3.6$ in $12 \%$ ethanol. Fig. 2 shows the modifications produced in the visible region of the absorption spectrum in the Mv3gl solution following copigment addition, and Table 1 collects the changes in the absorbance at $520 \mathrm{~nm}$. The addition of increasing levels of DHQ3gl to a constant anthocyanin concentration resulted in an increasing absorbance of the solution over all the visible range. In contrast with the observations made in other studies conducted in model solutions with different copigments (Berké \& De Freitas, 2005; Malaj, De Simone, Quartarolo, \& Russo, 2013; Mirabel, Saucier, Guerra, \& Glories, 1999), in this case hardly bathochromic shift in $\lambda_{\max }$ in the visible spectra of the copigmented solutions was observed, which might suggest a low capacity of binding of DHQ3gl to the flavylium form of the anthocyanin, possibly indicating that it is a poor electron donor.

The hyperchromic effect in the copigmented solutions was still noticeable 2 months after their preparation (Fig. 2B), being the relative increase in the absorbance at $520 \mathrm{~nm}$ in relation to the solution containing the anthocyanin alone even higher than the one observed in the first sampling (Table 1). Nevertheless, after 2 months of storage a decrease in the color intensity of the solutions was observed and a modification in the shape of the visible spectrum was also produced, suggesting that changes in the composition of the solutions might have been produced. Indeed a decrease in the concentrations of both Mv3gl and DHQ3gl in the solutions occurred (Fig. 3), which in the case of the anthocyanin accounted for $30 \%$ on average, irrespective of the presence and level of added copigment. Those decreases were not accompanied by significant formation of new compounds, namely new pigments (Fig. 3), contrary to what was observed in previous studies in our laboratory using catechins, flavonols or hydroxycinnamic acids as anthocyanin copigments (González-Manzano, Dueñas, RivasGonzalo, Escribano-Bailon, \& Santos-Buelga, 2009; Gómez-Míguez et al., 2006). These observations suggest that the presence of DHQ3gl did not confer additional stability to the anthocyanin and that the changes observed in the color of the solutions would be basically explained by the changes in the levels of original substrates and the copigmentation phenomenon itself.

\subsection{Influence of copigmentation in color parameters}

With the aim of evaluating the effect of copigmentation on the color expression of Mv3gl, chromatic analyses in the CIELAB space were performed, so as to visualize changes in the entire visible spectrum. Table 2 shows the mean values of the chromatic parameters for the different solutions, calculated after $2 \mathrm{~h}$ and 2 months of their preparation.

The addition of the copigment to the anthocyanin solution induced a decrease in lightness $\left(L^{*}\right)$ and a significant $(p<0.05)$ increase in saturation $\left(s_{\mathrm{uv}}^{*}\right)$ and chroma $\left(C^{*}\right)$, indicating a greater color intensity of copigmented solutions. Thus, the hyperchromic effect was associated to a darkening of the anthocyanin solutions and greater quantity of color and visual saturation. These changes were more marked with increasing copigment concentration, in agreement with previous studies using other cofactors (GonzálezManzano et al., 2009; Gordillo et al., 2012). Changes in the chromatic characteristics were still appreciated after 2 months of storage, although different behavior in the $h_{\mathrm{ab}}^{*}, a^{*}$ and $b^{*}$ parameters was observed in relation to the first sampling date. While at the beginning of the assay $(2 \mathrm{~h}$ ) the color of copigmented solutions shifted toward red-purple compared with the anthocyanin alone, after 2 month, the displacement was more toward red-orange colors.

In general, the higher the level of DHQ3gl in the solutions the higher was the decrease of $\Delta L^{*}$ and the increase of $\Delta h_{\mathrm{ab}}^{*}$, which means a shift toward red-orange and a darkening effect, which was more pronounced after 2 months of storage (Table 2). Simultaneously, chroma differences $\Delta C_{\mathrm{ab}}^{*}$ tended to rise resulting in an increasing vivid effect, more marked than lightness and hue trends. On the other hand, by comparing the relative contributions of lightness $(\% \Delta L)$, chroma $(\% \Delta C)$, and hue $(\% \Delta H)$ obtained at each molar ratio, it was observed that for all the molar ratios tested, the absolute color differences induced by copigmentation were mainly due to quantitative changes $(\% \Delta L+\% \Delta C>95 \%$ at $2 \mathrm{~h}$ of reaction, and between $69 \%$ and $95 \%$ after 2 months of storage) and to a lesser extent to the qualitative ones $(\% \Delta H<5 \%$ at $2 \mathrm{~h}$ of reaction, and between $4 \%$ and $30 \%$ after 2 months of storage) (Fig. 4). Besides, a different behavior of quantitative changes depending on the time of reaction could be observed, being the weight of the modifications in chroma more marked than those in lightness at $2 \mathrm{~h}$, whereas the opposite was observed after 2 months. Moreover, increasing concentration of DHQ3gl differently influenced the pattern of evolution of these parameters during the assay, with a notable decrease in lightness from low to high molar ratios at both sampling times. The chroma and hue contributions were in general more variable according to the time of reaction, noting a significant decrease in chroma and increase in hue after 2 months, with the increase in DHQ3gl concentration, in opposition to what was observed $2 \mathrm{~h}$ after the preparation of the solutions (Fig. 4).

In order to establish whether the changes generated in the chromatic parameters were visually relevant, the color differences induced by copigmentation ( $\Delta E_{\mathrm{ab}}^{*}$ ) were also calculated (Table 2 ). It has been indicated that a non-trained human eye is able to distinguish two colors when the $\Delta E_{\mathrm{ab}}^{*}$ is greater than 3 units CIELAB (Martínez, Melgosa, Pérez, Hita, \& Negueruela, 2001). According to this criterion, only the color changes induced at the highest copigment concentration (pigment:copigment molar ratio 1:5) would be 


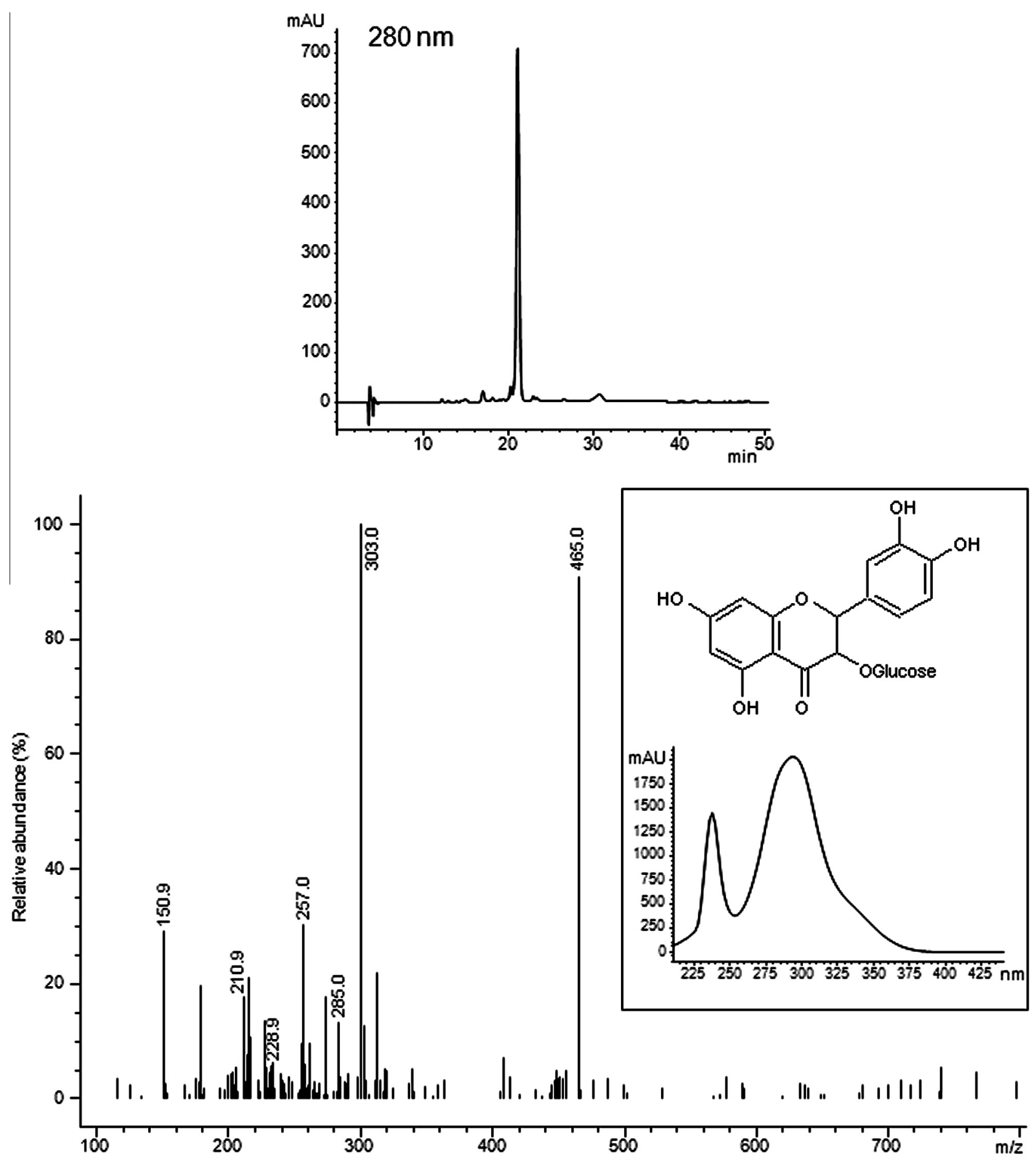

Fig. 1. HPLC chromatogram recorded at $280 \mathrm{~nm}$ of the isolated dihydroquercetin-3-O-glucoside, and UV and ESI/MS(-) mass spectra of the compound.

visually relevant in the solutions after $2 \mathrm{~h}$ of preparation $\left(\Delta E_{\mathrm{ab}}^{*} 3.94\right)$. The differences between anthocyanin and copigmented solutions were, however, more marked after 2 months of storage, at which the change of color could be already considered visually evident in the solution with molar ratio $1: 2\left(\Delta E_{\mathrm{ab}}^{*} 2.93\right)$, and was highly noticeable in that with ratio $1: 5\left(\Delta E_{\mathrm{ab}}^{*} 6.44\right)$.

\subsection{Thermodynamic measurements}

As described above, the changes in the visible spectrum of the Mv3gl solution in the presence of increasing concentrations of
DHQ3gl clearly showed the production of a hyperchromic effect, hardly inducing a bathochromic displacement $(1-2 \mathrm{~nm})$ of $\lambda_{\max }$ (Table 1, Fig. 2). This phenomenon might indicate the alteration in the hydration equilibrium and a little change in the deprotonation of flavylium ion. Therefore, much higher modification of the hydration constant $\left(K_{\mathrm{h}}\right)$ than of the proton transfer constant $\left(K_{\mathrm{a}}\right)$ should occur (González Manzano, 2007).

In order to determine the modification of the anthocyanin equilibria in the presence of DHQ3gl, assays were carried out in solutions $(0.1 \mathrm{mM}$ in citrate-phosphate buffer, $\mathrm{pH}$ 3.6, $12 \%$ ethanol, and $1 \mathrm{M}$ of ionic strength) of $\mathrm{Mv3gl}$ alone and with increasing 

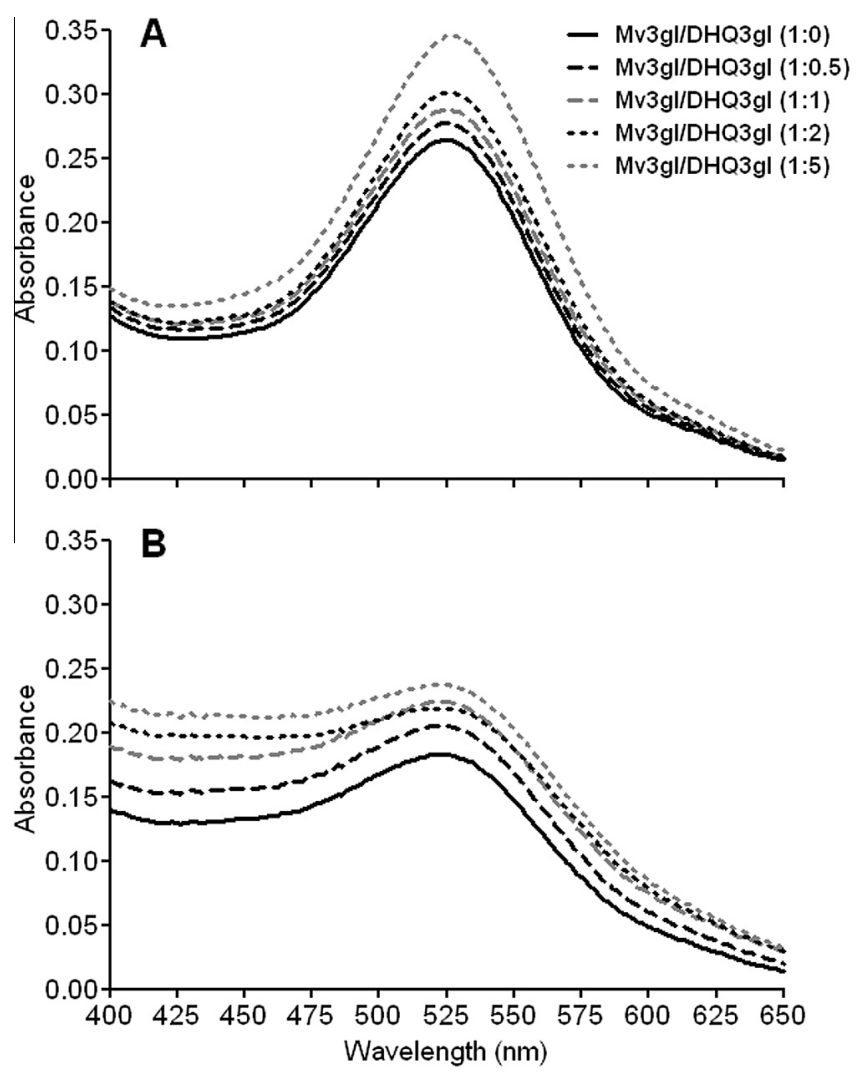

Fig. 2. Absorbance spectra of malvidin-3-O-glucoside $(0.41 \mathrm{mM})$ with different molar ratios of dihydroquercetin-3-O-glucoside at $2 \mathrm{~h}(\mathrm{~A})$ and 2 months (B) of assay $\left(25^{\circ} \mathrm{C}, \mathrm{pH} 3.6\right)$.

Table 1

Magnitude of the hyperchromic shift at $520 \mathrm{~nm}$ in solutions of malvidin-3-O glucoside $(0.41 \mathrm{mM})$ containing increasing molar ratios of dihydroquercetin-3-Oglucoside at $\mathrm{pH} 3.6$, determined $2 \mathrm{~h}$ and 2 months after the preparation of the mixtures.

\begin{tabular}{lcccc}
\hline \multirow{2}{*}{ Time } & \multicolumn{4}{l}{$\left[\left(A-A_{0}\right) / A_{0} \times 100\right]^{\mathrm{a}}$} \\
& \multicolumn{3}{l}{ Molar ratio (pigment:copigment) } & \\
\cline { 2 - 5 } & $1: 0.5$ & $1: 1$ & $1: 2$ & $1: 5$ \\
\hline $2 \mathrm{~h}$ & 4.58 & 8.78 & 13.36 & 29.01 \\
2 months & 12.02 & 22.40 & 19.67 & 29.50
\end{tabular}

${ }^{\mathrm{a}} A$ and $A_{0}$ are the absorbances of the solutions at $520 \mathrm{~nm}$ in the presence and absence of copigment, respectively.

molar ratios of DHQ3gl. A low concentration of the anthocyanin was used in these assays to prevent self-association and thus evaluate the copigmentation effect without interference (Teixeira et al., 2013). The $p K^{\prime}{ }_{h}$ values of Mv3gl in the presence of different concentrations of DHQ3gl were calculated according to Dangles et al. (1993b). It was observed that $p K^{\prime}{ }_{h}$ values significantly increases (Tukey HSD test, $p<0,05$ ) with the increase in the level of copigment in the solution, from 2.61 (Mv3gl reference solution) to a maximum value of 2.74 obtained in the solution with the highest concentration of DHQ3gl (pigment/copigment molar ratio 1:5). In addition, the outcomes for the intermediate molar ratios were 2.65 (1:0.5), 2.66 (1:1), and 2.67 (1:2). These values are lower than those observed when flavanols were used as copigments, where an increase from a $p K^{\prime}{ }_{\mathrm{h}}$ value of 2.93 in the solution of $\mathrm{Mv} 3 \mathrm{gl}$ alone to values ranging between 3.06 and 3.19 in the solutions containing Mv3gl:flavanol molar ratios of 1:5 was observed (GonzálezManzano et al., 2009). Other kinetic and thermodynamic parameters were also determined. Thus, a constant of copigmentation
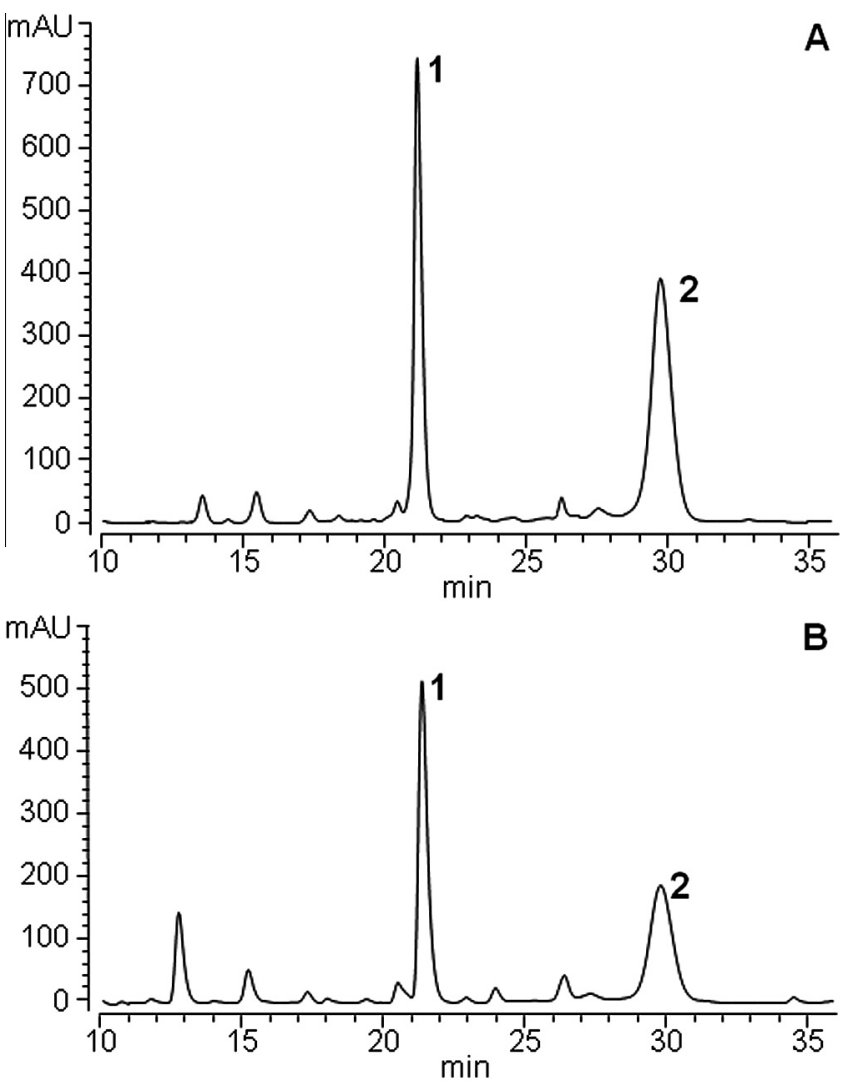

Fig. 3. HPLC chromatograms recorded at $280 \mathrm{~nm}$ of the solution of Mv3gl:DHQ3gl (1:1) obtained $2 \mathrm{~h}$ after preparation $(\mathrm{A})$ and after 2 months of storage at $25^{\circ} \mathrm{C}(\mathrm{B})$. Peak reference: 1 , DHQ3gl; 2, Mv3gl.

$\left(K_{\mathrm{c}}\right)$ of $191.4 \mathrm{M}^{-1}$ was calculated, assuming a stoichiometric ratio Mv3gl:DHQ3gl of 1:1. This value is of the same order of magnitude, and even higher, to that reported by other authors in model solutions of Mv3gl copigmented with different flavanols (Dangles, Stoeckel, Wigand, \& Brouillard, 1992; Francia-Aricha, RivasGonzalo, \& Santos-Buelga, 1998; Mirabel et al., 1999) or phenolic acids (Dimitric-Markovic et al., 2000; Malaj et al., 2013), indicating similar ability of DHQ3gl to act as anthocyanin copigment as those compounds. However, it was lower (5-10 times less) to that obtained in studies with flavonols (Baranac et al., 1996; Lambert et al., 2011), which would thus appear as better copigments than dihydroflavonols. This could be logical considering the non-planar structure of these latter due to the presence of asymmetric carbons at positions 2 and 3 that, as in the case of flavanols, difficult a closer approach to the anthocyanin.

The Gibbs energy variation $\left(\Delta G^{0}\right)$ represents the changes in the chemical potential of the system, and it is used as a measure of the ease with which the copigmentation process occurs. Values of $\Delta G^{0}<0$ indicate that the copigmentation process is favored. The value of the $\Delta G^{0}$ obtained in this study for DHQ3gl was $-12.8 \mathrm{~kJ} /$ mol K, indicating its ability to act as Mv3gl copigment. This value was similar to those observed by other authors for different phenolic acids (caffeic, coumaric, vanillic, syringic), flavan-3-ols ((+)catechin, (-)-epicatechin, procyanidin dimmer), and flavonols (quercetin, rutin) (Baranac et al., 1996; Lambert et al., 2011; Malaj et al., 2013; Oszmianski, Bakowska, \& Piacente, 2004).

Comparisons about the relative ability of different compounds to act as anthocyanin copigments should, nevertheless, be interpreted with caution, as different conditions of assay may be used in each case. Actually, factors such as $\mathrm{pH}$, temperature, ionic strength, type of buffer or substrates concentration greatly modify 


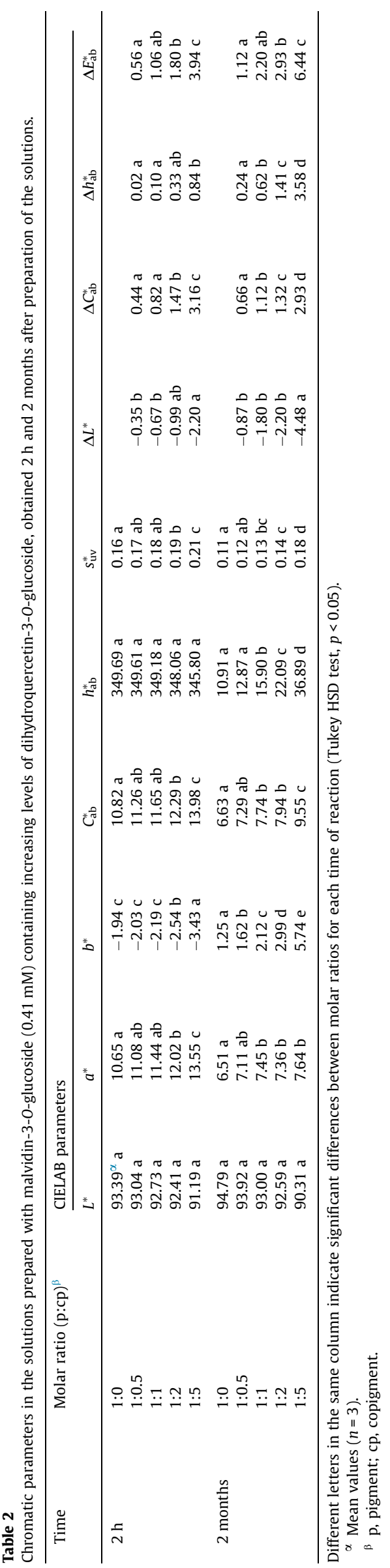

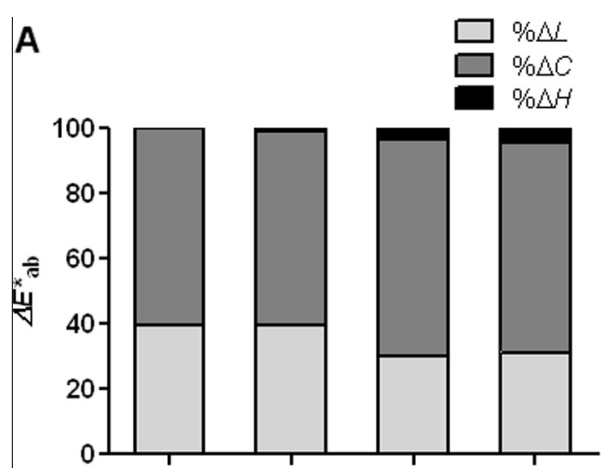

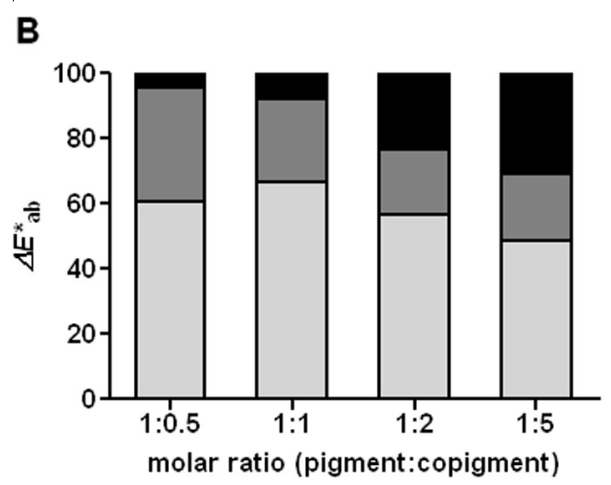

Fig. 4. Relative contribution of the three color attributes (lightness $\% \Delta L$, chroma $\% \Delta C$, and hue $\% \Delta H$ ) to the total color difference for Mv3gl:DHQ3gl solutions as a function of the molar ratio and time of reaction (A, 2 h; B, 2 months).

the kinetic and thermodynamic constants of the process. Thus, the optimum copigmentation $\mathrm{pH}$ differs according to the pigment and copigment tested (Williams \& Hrazdina, 1979), and complex formation decreases with the increase in the temperature, because it is an exothermic process (Dangles \& Brouillard, 1992; Malaj et al., 2013). Salts and ions $\left(\mathrm{K}^{+}, \mathrm{Na}^{+}, \mathrm{Cl}^{-}\right)$compete with flavylium ion by molecules of water, so that the ionic strength also influences the extent of the hydration reaction (Dangles et al., 1992). Solvents also modify the copigmentation behavior. For instance, Mirabel et al. (1999) obtained a $K_{\mathrm{c}}$ of $101 \mathrm{M}^{-1}$ for Mv3gl and epicatechin in aqueous solution and of $157 \mathrm{M}^{-1}$ in $10 \%$ ethanol. Finally, the extent of copigmentation depends not only of the pigment:copigment ratio, but it is also modified by the absolute concentrations of the substrates.

\section{Conclusion}

All in all, the obtained results allowed concluding that dihydroquercetin-3-O-glucoside can act as an anthocyanin copigment, similar to other usual wine components like flavanols or phenolic acids, although apparently less efficient than flavonols. Nevertheless, the high levels of dihydroflavonols (i.e., DHQ3gl and dihydroquercetin-3-O-rhamnoside) existing in Malbec grapes and wines in relation to other non-anthocyanin phenolics (Fanzone, 2012) should make this family of compounds particularly important to explain the color expression and definition in young red wines of this variety. Copigmentation with dihydroflavonols does not seem, however, to be a critical factor to explain the maintenance of the color during wine ageing and storage, as apparently it does not confer additional protection against anthocyanin degradation nor favor the significant formation of new pigments. The extent of these observations is limited by the difficulty to extrapolate them to the wine matrix, whose complexity favors multiple complementary reactions. More studies are also required 
to evaluate the influence of genetic, viticultural and enological variables on the biosynthesis and accumulation of this kind of copigments in grape berries and its expression into the wine, in order to better understand their contribution to the color and to achieve the desired effects.

\section{Conflict of interest}

The authors declare no competing financial interest.

\section{Acknowledgments}

This research was supported by Instituto Nacional de Tecnología Agropecuaria (INTA, Argentina), Project PNAlyAV 1130043 and "Programa de Perfeccionamiento 2013, Resolución $\mathrm{N}^{\circ} 478 / 13$ ". The GIP-USAL is financially supported by the Spanish "Ministerio of Economia y Competitividad" (MINECO) through the projects CSD2007-00063 (Fun-c-Food, Consolider-Ingenio 2010 Programme) and BFU2012-35228. The authors are grateful to Bodegas Esmeralda S.A. for providing the grapes of this assay.

\section{References}

Abad-García, B., Garmón-Lobato, S., Berrueta, L. A., Gallo, B., \& Vicente, F. (2009). A fragmentation study of dihydroquercetin using triple quadrupole mass spectrometry and its application for identification of dihydroflavonols in Citrus juices. Rapid Communications in Mass Spectrometry, 23, 2785-2792.

Baranac, J. M., Petranovic, N. A., \& Dimitric-Markovic, J. M. (1996) Spectrophotometric study of anthocyanin copigmentation reactions. Journal of Agricultural and Food Chemistry, 44, 1333-1336.

Berké, B., \& De Freitas, V. A. P. (2005). Influence of procyanidin structures on their ability to complex with oenin. Food Chemistry, 90, 453-460.

Boido, E., García-Marino, M., Dellacassa, E., Carrau, F., Rivas-Gonzalo, J. C., \& Escribano-Bailón, M. T. (2011). Characterisation and evolution of grape polyphenol profiles of Vitis vinifera L. cV. Tannat during ripening and vinification. Australian Journal of Grape and Wine Research, 17, 383-393.

Boulton, R. (1996). A method for the assessment of copigmentation in red wines. In Presented at the forty-seventh annual meeting of the American society for enology and viticulture, Reno, NV, USA.

Boulton, R. (2001). The copigmentation of anthocyanins and its role in the color of red wine: A critical review. American Journal of Enology and Viticulture, 52, 67-87.

Brouillard, R., Mazza, G., Saad, Z., Albrechtgary, A. M., \& Cheminat, A. (1989). The copigmentation reaction of anthocyanins - A microprobe for the structural study of aqueous-solutions. Journal of the American Chemical Society, 111, 2604-2610.

Brouillard, R., \& Dangles, O. (1994). Anthocyanin molecular interactions: The first step in the formation of new pigments during wine aging. Food Chemistry, 51, 365-371.

Dangles, O., \& Brouillard, R. (1992). Polyphenol interactions - The copigmentation case - Thermodynamic data from temperature-variation and relaxation kinetics - Medium effect. Canadian Journal of Chemistry, 70, 2174-2189.

Dangles, O., Stoeckel, C., Wigand, M., \& Brouillard, R. (1992). Two very distinct types of anthocyanin complexation - Copigmentation and inclusion. Tetrahedron Letters, 33, 5227-5230.

Dangles, O., Saito, N., \& Brouillard, R. (1993a). Anthocyanin intramolecular copigment effect. Phytochemistry, 34, 119-124.

Dangles, O., Saito, N., \& Brouillard, R. (1993b). Kinetic and thermodynamic control of flavylium hydration in the pelargonidin cinnamic acid complexation-origin of the extraordinary flower color diversity of Pharbitis nil. Journal of the American Chemical Society, 115, 3125-3132.

Dimitric-Markovic, J., Petranovic, N. A., \& Baranac, J. M. (2000). A spectrophotometric study of the copigmentation of malvin with caffeic and ferulic acids. Journal of Agricultural and Food Chemistry, 48, 5530-5536.

Escribano-Bailón, M. T., \& Santos-Buelga, C. (2012). Anthocyanin copigmentation Evaluation, mechanisms and implications for the colour of red wines. Current Organic Chemistry, 16, 715-723.

Fanzone, M., Zamora, F., Jofré, V., Assof, M., \& Peña-Neira, A. (2011). Phenolic composition of Malbec grape skins and seeds from Valle de Uco (Mendoza, Argentina) during ripening. Effect of cluster thinning. Journal of Agricultural and Food Chemistry, 59, 6120-6136.

Fanzone, M. (2012). Caracterización de la composición fenólica de uvas y vinos de la variedad Malbec (Vitis vinifera L.): su relación con el origen geográfico, factores vitivinícolas y valor comercial (Doctor of Enology and Biotechnology thesis) Tarragona, España: Universidad Rovira i Virgili. URL http://www.tdx.cat.
Fanzone, M., Zamora, F., Jofré, V., Assof, M., Gómez-Cordovés, C., \& Peña-Neira, A. (2012). Phenolic characterisation of red wines from different grape varieties cultivated in Mendoza province (Argentina). Journal of the Science of Food and Agriculture, 92, 504-518.

Fernández, J., Santamaría, C., \& Sparza, I. (2006). Chromatic characterization of three consecutive vintages of Vitis vinifera red wine. Effect of dilution and iron addition. Analytica Chimica Acta, 563, 331-337.

Francia-Aricha, E. M., Rivas-Gonzalo, J. C., \& Santos-Buelga, C. (1998). Effect of malvidin-3-monoglucoside on the browning of monomeric and dimeric flavanols. Zeitschrift für Lebensmitteluntersuchung und -Forschung A, 207, $223-228$.

Gómez-Míguez, M., González-Manzano, S., Escribano-Bailón, M. T., Heredia, F. J., \& Santos-Buelga, C. (2006). Influence of different phenolic copigments on the color of malvidin-3-glucoside. Journal of Agricultural and Food Chemistry, 54, 5422-5429.

González-Manzano, S., Rivas-Gonzalo, J. C., \& Santos-Buelga, C. (2004). Extraction of flavan-3-ols from grape seed and skin into wine using simulated maceration. Analytica Chimica Acta, 513, 283-289.

González Manzano, S. (2007). Antocianos y flavanoles en uvas y vino. Influencia de la composición en los procesos de copigmentación y estabilidad del color (Doctor of Philosophy thesis). España: Universidad de Salamanca.

González-Manzano, S., Dueñas, M., Rivas-Gonzalo, J. C., Escribano-Bailon, M. T., \& Santos-Buelga, C. (2009). Studies on the copigmentation between anthocyanins and flavan-3-ols and their influence in the colour expression of red wine. Food Chemistry, 114, 649-656.

Gordillo, B., Rodríguez-Pulido, F. J., Escudero-Gilete, M. L., González-Miret, M. L., \& Heredia, F. J. (2012). Comprehensive colorimetric study of anthocyanic copigmentation in model solutions. Effects of $\mathrm{pH}$ and molar ratio. Journal of Agricultural and Food Chemistry, 60, 2896-2905.

Goto, T., \& Kondo, T. (1991). Structure and molecular stacking of anthocyaninsflower color variation. Angewandte Chemie International Edition in English, 30, 17-33.

Heredia, F. J., Rivas-Gonzalo, J. C., Vicario, I. M. M., \& Santos-Buelga, C. (1998) Chromatic characterization of anthocyanins from red grapes - I. pH effect. Food Chemistry, 63, 491-498.

Heredia, F. J., Alvarez, C., González-Miret, M. L., \& Ramírez, A. (2004). CromaLab ${ }^{\circledR}$, análisis de color. Sevilla, Spain: Registro General de la Propiedad Intelectual SE1052-04.

Lago-Vanzela, E. S., Da-Silva, R., Gomes, E., García-Romero, E., \& HermosínGutiérrez, I. (2011). Phenolic composition of the edible parts (flesh and skin) of Bordo grape (Vitis labrusca) using HPLC-DAD-ESI-MS/MS. Journal of Agricultural and Food Chemistry, 59, 13136-13146.

Lambert, S. G., Asenstorfer, R. E., Williamson, N. M., Iland, P. G., \& Jones, G. P. (2011). Copigmentation between malvidin-3-glucoside and some wine constituents and its importance to colour expression in red wine. Food Chemistry, 125, 106-115.

Landrault, N., Larronde, F., Delaunay, J. C., Castagnino, C., Vercauteren, J., Merillon, J. M., et al. (2002). Levels of stilbene oligomers and astilbin in French varietal wines and in grapes during noble rot development. Journal of Agricultural and Food Chemistry, 50, 2046-2052.

Lorenzo, C., Pardo, F., Zalacain, A., Alonso, G. L., \& Salinas, M. R. (2005). Effect of red grapes co-winemaking in polyphenols and color of wines. Journal of Agricultural and Food Chemistry, 53, 7609-7616.

Malaj, N., De Simone, B. C., Quartarolo, A. D., \& Russo, N. (2013). Spectrophotometric study of the copigmentation of malvidin-3-O-glucoside with $p$-coumaric, vanillic and syringic acids. Food Chemistry, 141, 3614-3620.

Martínez, J. A., Melgosa, M., Pérez, M. M., Hita, E., \& Negueruela, A. I. (2001). Note: Visual and instrumental colour evaluation in red wines. Food Science and Technology International, 7, 439-444.

Masa, A., Vilanova, M., \& Pomar, F. (2007). Varietal differences among the flavonoid profiles of white grape cultivars studied by high-performance liquid chromatography. Journal of Chromatography A, 1164, 291-297.

Mirabel, M., Saucier, C., Guerra, C., \& Glories, Y. (1999). Copigmentation in model wine solutions: Occurrence and relation to wine aging. American Journal of Enology and Viticulture, 50, 211-218.

Monagas, M., \& Bartolomé, B. (2009). Anthocyanins and anthocyanin-derived compounds. In M. V. Moreno-Arribas \& C. Polo (Eds.), Wine chemistry and biochemistry (pp. 439-456). New York, USA: Springer.

Oszmianski, J., Bakowska, A., \& Piacente, S. (2004). Thermodynamic characteristics of copigmentation reaction of acylated anthocyanin isolated from blue flowers of Scutellaria baicalensis Georgi with copigments. Journal of the Science of Food and Agriculture, 84, 1500-1506.

Santos-Buelga, C., \& De Freitas, V. (2009). Influence of phenolics on wine organoleptic properties. In M. V. Moreno-Arribas \& C. Polo (Eds.), Wine chemistry and biochemistry (pp. 527-569). New York, USA: Springer.

Teixeira, N., Cruz, L., Brás, N. F., Mateus, N., Ramos, M. J., \& De Freitas, V. (2013). Structural features of copigmentation of oenin with different polyphenol copigments. Journal of Agricultural and Food Chemistry, 61, 6942-6948.

Williams, M., \& Hrazdina, G. (1979). Anthocyanins as food colorants: Effects of pH on the formation of anthocyanin-rutin complex. Journal of Food Science, 44, 66-68. 